is possible that this change was brought about by an improvement that was made in the stability of the platform which held the S's forearm. Such an improvement would have a greater effect at intensity levels near the threshold. A similar change in the steepness at near-threshold intensities was seen in the grouped data comparing all $S s$ from the two experiments (a total of $15 \mathrm{Ss}$ ).

The results are accepted as evidence that the psychological mechanism by which people are able to make intensity judgments remains relatively stable, at least for the period of time ( 3 years) used in this experiment. The data may also be accepted as evidence of the reproducibility of results using direct scaling procedures for vibrotaction.

\section{REFERENCES}

HELLMAN, R. P., \& ZWISLOCKI, J. Monaural loudness function at $1,000 \mathrm{cps}$ and interaural summation. Journal of the Acoustical Society of America, 1963,55. 856-865.

STEVENS, S. S. The measurement of loudness. Journal of the Acoustical Society of America, 1955, 27, 815-829. STEVENS, S. S. The direct estimation of sensory magnitude: Loudness. American Journal of Psychology, 1956, 69, 1-25.

STEVENS, S. S. Problems and methods of psychophysics. Psychological Bulletin, 1958, 54, 177-196.

VERRIILO, R. T., FRAIOLI, A. J., \& SMITH, R. L. Sensation magnitude of vibrotactile stimuli. Perception \& Psychophysics, 1969, 6A, 366-372.

\title{
The variety effect in free recall as a function of prerecall activity*
}

\author{
WALTER F. DAVES and ROGER C. RINN \\ Georgia State University, Atlanta, Ga. 30303
}

The enhancement of free recall of object categories represented by varied, as opposed to repeated, specimens was studied when Ss recalled immediately after presentation of the stimuli vs when they worked arithmetic problems for $1 \mathrm{~min}$ before recalling. All Ss recalled three times, the second and third recalls in all cases being preceded by $1 \mathrm{~min}$ of arithmetic. Results indicated no change in recall over the three trials. However, the varied categories were recalled better than the repeated categories, and the difference was reduced when interpolated activity was required. The interpolated activity was more effective for the female Ss and appeared to depend upon the particular categories that were varied or repeated. The findings were interpreted as indicating the contribution of retrieval processes to the variety effect.

Several recent experiments have reported that free recall of categories of objects is better when the categories are represented by several different specimens than when they are represented by the same specimen repeated an equivalent number of times (Bevan, Dukes, \& Avant, 1966; Daves \& Adkins, 1969). This effect has been termed the variety effect (VE) and has been observed in children as well as in college students (McCarson \& Daves, in press). In one study, Daves \& Rinn (1971) compared the recall of varied and repeated categories in Ss receiving one, two, three, or four exposures to the category. Repetition was found to inhibit recall up to three exposures, while variation produced an increase in recall over the first three exposures. After 2 weeks, recall was essentially the same for the varied and repeated

*This research was partly supported by funds from the National Science Foundation. Grant No. GU 2751, to Georgia State University. Requests for reprints should be directed to Dr. Walter F. Daves, Department of Psychology, Georgia State University. 33 Gilmer Street, S.E., Atlanta, Georgia 30303. categories. Since category variation was manipulated with Ss, it was suggested that the effect might be due to the establishment of priorities in a limited-capacity retrieval system.

The present experiment was conducted to obtain further information on the "localization" of the phenomenon, i.e., whether or not it is related to output processes. Since all of the experiments reporting the effect thus far have had Ss recall immediately after presentation of the stimuli, the question arises as to whether or not the effect is predominantly related to short-term memory, or if it also occurs with longer retention intervals. Although delayed recall has been employed in studies of the VE (e.g., Bevan et al, 1966; Daves \& Rinn, 1970), these studies employed an immediate recall for all Ss as well, which introduces the factor of immediate rehearsal. Consequently, in the present study an arithmetic task was interpolated between exposure and recall for half of the Ss, the expectation being that, if the VE were related to short-term retrieval organization, the difference in recall between varied and repeated categories would be reduced when interpolated activity was required.

SLBJECTS AND DESIGN

The Ss were 24 male and 24 female volunteers from introductory psychology classes, who served in the experiment as part of the course requirement. They were tested in groups varying in size from one to six. Half of the Ss were assigned to Group IA-M, which received $1 \mathrm{~min}$ of interpolated activity (working arithmetic problems) before recall, and the other half recalled immediately (Group IA-NM). Within the above subdivision, half of the Ss in each group received Category Arrangement A (CA-A) and half received CA-B (see below). All Ss received three recall trials (RT) and two levels of variety (VL). For each $S$ half of the categories were represented by four identical specimens ( $R$ categories), and half were represented by four different specimens (V categories). Thus, there were three between-S variables: sex, IA, and $C A$; and there were two within-S variables: $\mathrm{RT}$ and VL. STIMULUS MATERIALS

Stimuli consisted of 72 color slides representing 18 categories of common objects. All objects were photographed against a common off-white background. Each of the categories was represented by four different specimens (e.g., for the category "watches," there were four different watches), and there were four identical photographs of each specimen. Thus, each category could be represented by one of the four specimens repeated four times or by four different specimens. Two sets of 72 slides were selected. For the slides in Category Arrangement $A$, the $R$ categories consisted of ash trays, books, cereal boxes, chairs, keys, lamps, pens, rings, and shoes; and the $\mathrm{V}$ categories were watches, typewriters, flowers, knives, candles, pillows, bottles, balls, and purses. For the slides in Arrangement $B$ the arrangement was reversed. Thus, for example, $S$ s in Group CA-A viewed four different watches and the same ash tray repeated four times; Ss in Group CA-B viewed the same watch repeated four times and four different ash trays. In total, each $\mathrm{S}$ viewed each category four times, once in each block of 18 trials. Within blocks the categories were arranged haphazardly.

The slides were presented with a Kodak Carousel projector whose internal shutter had been modified with a solenoid latch to permit control of exposure duration. Exposure duration was $0.5 \mathrm{sec}$, and the interval between onsets of successive slides was $2 \mathrm{sec}$. These intervals were controlled by a Hunter Model 1514 timer and monitored periodically with a Tektronix Model 503 oscilloscope 
drisen by a silicon photocell located in the center of the projection screen. PROCEDURE

Lpon entering the laboratory each $\mathrm{S}$ was given a pencil and a pad of paper and was seated in a desk chair. The following instructions were read: "This is a study of visual perception. I'm going to show vou some pictures of objects. Pay close attention to each individual object. After you have seen them all, I'll ask you to recall the objects. Please don't talk or write during the session."

Next, the lights in the room were turned off, and the slides were presented. The Ss in Group IA-NM then were asked to recall as many of the objects as they could. At the end of $2 \mathrm{~min}$, they were given a sheet of three-column addition problems and instructed to work as many of them as they could. At the end of $1 \mathrm{~min}$, a second 2 -min recall trial was begun, followed by another round of addition problems $(1 \mathrm{~min})$ and a third 2-min recall trial. The procedure for Group IA-M was the same, except that these Ss worked the arithmetic problems for $1 \mathrm{~min}$ before the first recall trial. Thus, the difference between Groups IA-M and IA-NM was in the presence or absence of the interpolated activity before the first recall trial. The second and third recall trials were preceded by the arithmetic for both groups.

\section{RESULTS}

Each S's response sheet was scored for category recall. A category was scored correct if any object within it that was presented was recalled. When more than one object per category was recalled, the additional objects were not counted. Each $S$ thus had six recall scores, one for the $\mathrm{R}$ categories and one for the $\mathrm{V}$ categories for each of the three recall trials.

Since analysis of variance revealed that none of the effects involving recall trials even approached significance, data were pooled across trials for purposes of further analysis. The main results are presented in Fig. 1. The overall effect of variety was significant $[F(1,200)=48.61]$, with 6.3 of the $V$ categories and 5.3 of the $R$ categories being recalled. Also, the VL by IA interaction, upon which the present experiment is focused, was significant $[F(1,200)=7.78]$. The interpolated activity reduced recall for the $\mathrm{V}$ categories $[\mathrm{IA}-\mathrm{NM}=6.5, \mathrm{IA}-\mathrm{M}=6.1$; $F(1,200)=5.00, \quad p<.05]$ and produced an insignificant increase in recall for the $R$ categories $[\mathrm{I} \mathrm{A} \cdot \mathrm{NM}=5.2, \quad \mathrm{IA} \cdot \mathrm{M}=5.5$; $F(1,200)=3.57, p>.05]$. However, a large portion of the reduction in the variety effect with the interpolated activity was contributed by the female Ss, as indicated by a significant interaction between VL, IA, and sex

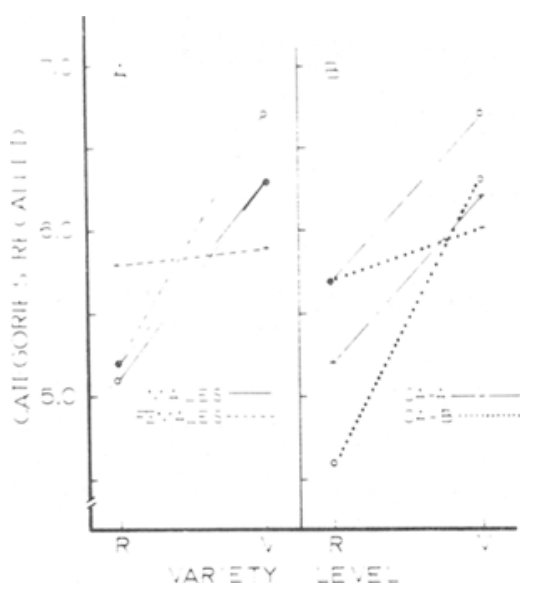

Fig. 1. Number of categories recalled as a function of intracategory variation (variety level). Panel A shows the interaction between VL, CA, and sex. The pluses refer to the IA-M condition, the open circles to the IA-NM condition. The solid lines indicate male Ss, the dashed lines female Ss. Panel B indicates the interaction between VL, IA, and CA. The pluses and open circles represent the IA-M and IA-NM conditions, respectively; the broken line refers to the $\mathrm{CA}-\mathrm{A}$ condition, the dotted line to the CA-B condition. See text for explanation.

$[F(1,200)=6.20]$ and analysis of the simple effects of this interaction. There was a significant simple interaction between VL and IA for the females $(F=13.57)$ but not the males $(\mathrm{F}=0.00)$.

The particular categories assigned to the $V$ or the $R$ group also influenced the effect of interpolated activicy on the variety effect, evidenced by the significant VL by IA by CA interaction $[F(1,200)=5.71]$. Analysis of simple effects reveals that, while there were significant effects of both VL and IA for both category-assignment conditions ( $p<.005$ in all cases), Category Assignment B also showed a significant interaction between VL and IA $(F=25.71)$. Thus, the superiority of recall for the $V$ as opposed to the $R$ categories was evident in the absence of interpolated activity $[6.3$ vs 4.6 ; $F(1,200)=74.29]$, but not when the activity was required $[R=5.7, V=6.0$; $F(1,200)=1.431$. In other words, the reduction in the variety effect due to interpolated activity was mainly a contribution of Category Arrangement $B$.

The CA by IA interaction $[F(1,40)=4.62$, p. $<.05]$, although qualified by the significant three-way interactions described above, indicates that there was poorer recall for Category Arrangement B than for
Arrangement $A$ with no interpolated activity $[12.4$ vs $11.0 ; F(1,40)=6.49$, $\mathrm{p}<.025]$, but no difference between the two arrangements when interpolated activity was required $(\mathrm{A}=11.4, \mathrm{~B}=11.6 ; \mathrm{F}<1.00)$.

\section{DISCUSSION}

This experiment again demonstrates rather clearly that recall is better for varied than for repeated categories. The overall effect, however, was reduced significantly when the first recall was preceded by interpolated activity. Such a result is in line with the reasoning that at least part of the VE is due to retrieval processes in short-term memory. The interpolated activity does not, however, completely abolish the effect. The residual VE could be due to the fact that working the arithmetic problems did not completely interfere with covert rehearsal, or it could be due to the operation of processes during encoding or storage of the material. The first alternative could be ruled out by having $S$ perform a more demanding task, such as alternating serial subtraction and addition, and the second by determining the sensitivity of the VE to variables such as exposure duration and interexposure interval. A report dealing with the second alternative is in preparation. ${ }^{1}$

Our findings also indicate that the effect of intracategory variation and its modification by prerecall activity are sensitive to at least two other variables, including sex of $S$ and the specific categories represented by varied or repeated specimens. The significant interactions involving $\mathrm{VL}, \mathrm{CA}$, and sex point up this fact. While we do not have data to support this interpretation at present, it would appear that subject differences in regard to the meaningfullness of the particular categories employed must be considered in any explanation of these interactions and that some categories are more influenced by variation of specimens than are others.

\section{REFERENCES}

BEVAN, W DUKES, W R \& AVANT, L. L The effect of variation in specific stimul on memory for their superordinates. American Journal of Psychology, 1966 , $79,250-257$

DAVES, W. F.. \& ADKINS, M. Stimulus variation and free recall: A confirmation. American Journal of Psychology, 1969, $82,122-124$

DAVES, W. F. \& RINN, R. C. Free recall of object categories as a function of number of presentations of varied or repeated specimens. Psychonomic Science, 1971, 22, 207-209.

MCCARSON. C., \& DAVES, W. F. Free recal of object names in preschool children as a function of intracategory variation. Developmental Psvchology, in press. NOTE

1. Daves, W. F.. \& Rinn, R. C. The effect of stimulus duration and interstimulus in terval on the superiority in recall of varied over repeated categories. Manuscript in preparation. 